\title{
Algumas Palavras em Homenagem ao Pai
}

\author{
Ivonise Fernandes da Motta \\ Instituto de Psicologia-USP
}

\begin{abstract}
importância da figura paterna na constituição e desenvolvimento psíAquicos tem despertado constantes teorizações, estudos, pesquisas. Uma das questões básicas, trazidas à luz desde o início da Psicanálise, isto é, desde os trabalhos pioneiros do Pai da Psicanálise, S. Freud e seus "Estudos sobre a Histeria" é a importância da interdição. Interdição significando castração, ou seja, a possibilidade de renunciar à satisfação de um desejo. Função estruturante do psiquismo, a importância dada à interdição é inegável nos dias atuais. Mas, renunciar a um desejo com possibilidades de novos progressos rumo à conquista de independência, autonomia e consolidação da própria identidade é tarefa árdua e caracterizada por várias armadilhas no caminho. Um longo percurso será necessário para trilhar os vários entraves na direção do que, rotineiramente, chamamos "Elaboração Edípica". Ou, dizendo de outra maneira, a possibilidade de irmos além de nossos próprios pais, a possibilidade de ganharmos distância psíquica do casal original: a mãe e o pai. E do número 3 constituir-se o um. "Um" significando ident idade própria, um ser com uma maneira única e diferenciada de todas as demais.

Há muito já dizia o dito popular: "Falar é fácil, fazer é que são elas". Muitos passos serão necessários para atingir tal resultado ou tal conquista. Esse é o trabalho desenvolvido com nossos pacientes, no viver clínico cotidiano. E é essa nossa pesquisa que nos faz avançar, pouco a pouco, no caminho de maior conhecimento. A evolução trazida por meio das descobertas sobre o inconsciente mudam muitas das noções a respeito da natureza humana. Perder a crença quanto ao controle das próprias idéias, fantasias, dese-
\end{abstract}


jos é aceitar princípios de funcionamento mental muito diferentes dos tão difundidos e valorizados na atualidade: lógica, razão, discernimento etc...

Aparentemente, o que poderíamos chamar função paterna - Isto é, controle, lógica, princípio da realidade - conflitaria com o que chamamos intuição, sensibilidade, dúvida, anseio etc...

Valores narcísicos tão poderosos nos dias atuais tornaram-se vulneráveis e frágeis quando são confrontados com a força e importância de angústias, desejos e fantasias reprimidas. Seguindo as palavras do dito popular, é ferida narcísica difícil de aceitar "O homem não ser senhor do seu próprio castelo, não ser senhor de sua própria morada". E mitos tornaram-se desfeitos, ou perdem seu valor. Chegaríamos então a uma questão anterior, a possibilidade ou não da existência do desejo.

A teoria freudiana parte da premissa de que o desejo é inerente à alma humana. Ao aprofundarmos nossos conhecimentos sobre a constituição e desenvolvimento psíquicos, investigando transtornos mais graves e severos tais como as psicoses, estados borderlines ou fronteiriços, temos que adentrar a constatação da ausência de desejo. Ou seja, aqueles seres ou pacientes mais regredidos estariam fundamentalmente mobilizados por necessidades, isto é, muito aquém do que se poderia chamar desejo. Tanto a estrutura quanto o funcionamento psíquico desses pacientes teriam semelhanças com a dos bebês ainda em fase de constituição de um eu. Aquisições básicas da personalidade tais como discriminação e separação eu-outro, capacidade de sentir culpa ou preocupação, utilização de espaço e fenômenos transicionais seriam conquistas por vezes inatingíveis ou por demais distantes.

Sendo assim, a importância de um diagnóstico preciso do estado e funcionamento mental de qualquer paciente que venhamos a consultar e atender é imprescindível à possibilidade de compreensão tanto das necessidades quanto dos desejos daquele ser. Imprescindível à possibilidade de compreensão dos sintomas, queixas ou conflitos que teriam motivado aquele paciente em buscar ajuda psicoterápica.

Freud, ao iniciar seus trabalhos com as histéricas, descortina verdades, conflitos, aspectos da vida mental nunca antes desvelados. E, ao continuar 
suas pesquisas, vai adentrando estratos cada vez mais complexos do mundo mental. Tais descobertas levarão a reformulações teóricas importantes que serão comunicadas através de seus escritos. Podemos acompanhar seu trabalho metodológico rigoroso ao ler sua obra do início até o fim.

Tentar ter compreensão da histeria e seus significados é tarefa árdua. Árdua porque incluiria num primeiro vislumbre conter e discriminar o que poderíamos denominar "atuação". Semelhante a uma peça de teatro, os vários e diferentes atores representam personagens. Personagens que compõem tragédias, comédias e tantos outros dramas humanos. Emoções que podem despertar os mais variados sentimentos: empatia, proximidade, distância, identificação, etc... Mas, um ator, a maior parte do tempo, tem conhecimento de que aquelas palavras e atos dizem respeito apenas e tão somente àquele personagem em questão e àquela peça de teatro. Os contornos estão bem definidos. A histérica ou histérico teriam dificuldades em estabelecer limites quanto ao que é uma representação apenas, e o que é algo genuíno ou , poderíamos dizer, verdadeiro - isto é, o significado de verdade psíquica do ponto de vista mental.

As artes, em especial o teatro e o cinema, utilizam-se dessas constituições ao compor um cenário, uma cena. Ao focalizarem as trilhas musicais, ou tons musicais, eles são escolhidos para compor aspectos emocionais vividos pelo personagem. Um filme que traz muitas dessas facetas de maneira inegável é Ligações Perigosas. Em uma das cenas na qual atuam Michele Pfeifer e John Malkovich, o personagem tenta seduzir a mulher, causandolhe impacto. Os tons musicais que acompanham a cena seguem o caminho da manipulação e tentativas de controle que o personagem presentifica. Isto fica visível quando o ator segue a personagem que, ao reagir ao impacto despertado, vai correndo para seus aposentos. O personagem olha através do buraco da fechadura e, ao confirmar a reação estabelecida, sorri com ares de triunfo. A questão, portanto, era seduzir, era um teatro, eram tentativas de controle das emoções de um outro ser. Tratava-se, portanto, de um jogo. $\mathrm{O}$ jogo no qual o histérico em sua competitividade, tenta ganhar, tenta derrotar. 
Esse aspecto da histeria, a competição, nos leva a questão da castração. Aceitar ou não a superioridade de um rival. No triângulo original, é o homem a superioridade da figura paterna.

Lacan, ao continuar o trabalho desenvolvido por Freud, vai adentrar questões vitais sobre desejo. Vai desenvolver uma teoria e trabalhos clínicos que irão focalizar a linguagem e suas articulações nas possibilidades de inserção do desejo no psiquismo humano, incluindo a importância das várias e diferentes interdições desde a infância até a idade adulta. Foi tentando estabelecer alguma compreensão sobre o trabalho da chamada Escola Francesa de Psicanálise que assisti a alguns cursos ministrados pelo Professor Luiz Carlos Nogueira. Portanto, no lugar que corresponderia ao de filha pude ter algumas noções introdutórias dessa outra linha de pensamento e trabalho em Psicanálise. Mais tarde, ao tomar-me docente do Departamento de Psicologia Clinica, sua colega, nossa convivência teve fases de maior proximidade, quando trabalhamos juntos, ele chefe do Departamento e eu Coordenadora da Clínica Psicológica do mesmo Departamento. Várias tarefas de diferentes níveis de complexidade fizeram com que muitos derivativos do que se poderia chamar interdição fossem vividos. Tarefas que implicaram questões complexas com equipes de trabalho, grupos, aspectos burocráticos, aspectos hierárquicos, conflitos etc...

Através do trabalho compartilhado com o Professor Luiz Carlos e com vários componentes da Equipe da Clínica Psicológica pude acompanhar, passo a passo, a importância da interdição e suas conseqüências. Ou seja, a importância do lugar ocupado por cada um dos funcionários de acordo com a atividade realizada.

Diria, então, que pude observar e conviver com o Professor Luiz Carlos ao transmitir tanto em teoria - as idéias de Lacan e seguidores - quanto ao acompanhar suas atitudes, não somente enquanto professor mas também no lugar de chefe do departamento. Isso implicou em vivências das mais difíceis e conturbadas. Por exemplo, acontecimento dos mais difíceis vividos pelo Departamento, o roubo de certa quantia da secretaria da clínica. Não pretendia 
entrar em detalhes do fato, mas sim a comunicação de vivências que estavam permeadas por muitos conflitos, pressões, divergências etc...

Passaram-se décadas desde os tempos em que fiz o curso de graduação em Psicologia e as disciplinas de pós-graduação. E agora, o que posso visualizar cada vez mais, em precisão, é quanto a interdição pode estar presente não só nas palavras, mas principalmente nas atitudes, nos silêncios, no respeito às hierarquias, no respeito em ouvir as comunicações do outro etc... Diria que o estilo do Professor Luiz Carlos sempre foi imbuído de um tom de respeito. Pronto para ouvir, serenidade era uma qualidade no seu dia-adia. Mas atitudes significativas foram tomadas, por exemplo, convocando uma reunião com toda a equipe de funcionários da clínica Psicológica para avaliar o acontecido, o roubo, e suas implicações, tanto quanto à Instituição quanto às várias pessoas componentes da equipe.

Sendo assim, poderia dizer: muito jovem, aluna do professor Luiz Carlos, pude ouvir idéias... E mais tarde, com mais experiência, pude ver atitudes. E nos vários e diferentes aspectos do que se poderia denominar castração, diria que a atitude respeitosa foi uma constante reveladora. Revelação de um espaço fundamental do que denominamos na nossa prática cotidiana de castração ou interdição. Respeito, significando possibilidades de ouvir, observar, dizer, agir no contato com outros.

Gostaria, através dessas páginas escritas, deixar marcada a importância desse aspecto em seus diferentes ângulos (lugar de professor, colega, chefe) no conviver com o Professor Luiz Carlos. O que me faz concluir que quanto mais tivermos possibilidade de viver várias e diferentes castrações, mais teríamos possibilidades de enriquecimento e aprendizagem.

A morte do Professor Luiz Carlos tomou-nos de surpresa, não a esperávamos tão prematuramente. E essa foi mais uma castração que tivemos que aceitar. Quando perdemos nossos pais, tanto os de filiação primeira quanto os vários pais simbólicos adotados ao longo de nossas vidas, podemos requalificar cada vez mais o que denominamos interdição. O estarmos inexoravelmente sujeitos a leis que vão muito além de nós mesmo e que independem de nossas vontades, desejos ou controles. 
Homenagear o Professor Luiz Carlos, por tudo que representou e realizou no Departamento de Psicologia Clínica, e marcar sua presença desde os primórdios, os inícios da Psicologia Clínica no Instituto e seus desenvolvimentos posteriores, é, portanto, acompanhar a construção de um longo caminho histórico, permeado pela interdição e, portanto, pela função e pelo lugar do pai. $\mathrm{O}$ respeito pelas diferenças que possibilitou esse caminho - sua filiação em termos psicanalíticos e de trabalho é diferente da minha e de muitos colegas - aponta, mais uma vez, para o valor da constatação e da permanência do lugar do pai, quer em momentos de sucesso, quer em momentos de turbulência ou conflito.

E, para marcar mais uma vez, a importância da interdição, da filiação, do lugar do pai, gostaria de finalizar tomando emprestadas algumas palavras do pai em termos de filiação de idéias e de trabalho do Professor Luiz Carlos, Jacques Lacan ao dizer: "Se Deus não existir,... então tudo é permitido. Noção evidentemente ingênua, pois, nós, analistas, sabemos muito bem que se Deus não existir então absolutamente mais nada é permitido" (Lacan, 1954/1985, p. 165).

\section{Referências}

Freud, S. (1973). Obras completas (L. Lopes Ballesteros y de Torres, trad.). Madrid, España: Biblioteca Nueva.

Lacan, J. (1985) O Seminário. Livro 2: O eu na teoria de Freud e na técnica da psicanálise (M. C. L. Penot \& A. L. Quinet de Andrade, trads.). Rio de Janeiro: Jorge Zahar. (Trabalho original publicado em 1954)

Priszkulnik, L. (1986). Jogo e ilusão: O olho, a visão, a linguagem. Dissertação de Mestrado, Instituto de Psicologia da Universidade de São Paulo, São Paulo. 